\title{
Contact Active Antimicrobial Coatings Prepared by Polymer Blending
}

Rocío Cuervo-Rodríguez, ${ }^{1}$ Fátima López-Fabal, ${ }^{2}$ José L. Gómez-Garcés, ${ }^{2}$ Alexandra Muñoz-

Bonilla, ${ }^{3^{*}}$ Marta Fernández-García ${ }^{3^{*}}$

${ }^{1}$ Facultad de Ciencias Químicas, Universidad Complutense de Madrid, Avenida Complutense s/n, Ciudad Universitaria, 28040 Madrid, Spain

${ }^{2}$ Hospital Universitario de Móstoles, C/Río Júcar, s/n, 28935 Móstoles, Madrid, Spain

${ }^{3}$ Instituto de Ciencia y Tecnología de Polímeros (ICTP-CSIC), C/Juan de la Cierva 3, 28006 Madrid, Spain

Corresponding author: sbonilla@ictp.csic.es; martafg@ictp.csic.es

\section{ABSTRACT}

Herein, we prepare contact active antimicrobial films by simply blending cationic amphiphilic block copolymers with commercial polystyrene (PS). The copolymers were prepared by combining atom transfer radical polymerization (ATRP) and "click chemistry". A variety of copolymers were synthesized composed of a PS segment and an antimicrobial block bearing flexible side chain with thiazole and triazole groups, 4-(1-(2-(4-methylthiazol-5-yl)ethyl)-1H1,2,3-triazol-4-yl) butyl methacrylate (TTBM). The length of the TTBM block was varied as well as the alkylating agent. Different films were prepared from $\mathrm{N}, \mathrm{N}$-dimethylformamide (DMF) solution, containing variable PS- $b$-PTTBM/PS ratio: from 0 to 100 wt. $\%$. Remarkably, the blends films, especially those with 30 and 50 wt.\% of copolymers, exhibit excellent antimicrobial activities against Gram-positive, Gram-negative bacteria and fungi, even higher than films prepared exclusively from the cationic copolymers. Blends composed of $50 \mathrm{wt} \%$ of the copolymers present a more than $99.999 \%$ killing efficiency against the studied microorganisms. The better activity found in blends could be due to the higher roughness, which increases the surface area and consequently the contact with the microorganisms. These results 
demonstrated that the use of blends implies a reduction of the content of antimicrobial agent and also enhances the antimicrobial activity, providing new insights for the better designing of antimicrobial coatings.

Keywords: cationic polymers, quaternary ammonium, ATRP, click chemistry, antimicrobial, roughness, blend film surfaces.

\section{INTRODUCTION}

Microbial surface contamination involves a series of problems that includes the repeatedly transmission of diseases by contact and more important, the formation of biofilms, which have been associated with persistent infections. ${ }^{[1]}$ Biofilms represent communal structures of microorganisms encased in robust extracellular matrices of biomolecules onto surfaces, which often display resistance toward conventional antibiotics and disinfectant. ${ }^{[2]}$ Indeed, a great number of persistent infections are directly related to biofilms and are responsible for significant cases of mortality and morbidity in hospitalized patients. ${ }^{[3]}$ Besides, biofilm formation on surfaces can alter the performance of sensitive materials such as medical devices or implant. For all these reasons, there is a great need for preparation of surfaces with antimicrobial activity; coatings or impregnation of surfaces with antimicrobial agents could reduce surface contamination and the spread of infections and biofilm formation. ${ }^{[4,5]}$ There are two main approaches for preparing surfaces with antimicrobial capacities, physically incorporation of antimicrobial agents including antibiotics, quaternary ammonium compounds or silver ${ }^{[6-8]}$ and covalent attachment of these agents. ${ }^{[9-11]}$ Although the first strategy is effective and its preparation is simple, the leaching of the antimicrobial agent involves serious limitations in terms of longevity, stability and environmental contamination. In contrast, the second strategy, which implies the covalent immobilization, conducts to antimicrobial surfaces with long-term effect and minimal cytotoxicity. However, current immobilization methods generally required multiple 
chemical reactions and modification steps. An alternative that include the advantages of both strategies, is polymer blending. Polymer blend technology ${ }^{[12]}$ is a commonly employed method in industry and convenient route for the development of new polymeric materials with tailored and enhanced properties. In this approach, an antimicrobial polymer is simple blending with a polymer matrix, imparting its activity to the material. Due to the low diffusion coefficients of polymers as a consequence of their high molecular weight, the leaching of the antimicrobial polymer is limited, ${ }^{[13]}$ and therefore their use leads to durable antimicrobial surfaces. Typically, cationic polymer bearing quaternary ammonium moieties with various alkyl chain lengths are employed because of their facile synthesis and excellent antimicrobial activity ${ }^{[14-17]}$. Remarkably, our group has designed and synthesized methacrylic polymers bearing two quaternary ammonium group per monomeric units. ${ }^{[18]}$ These structures were based on quaternized 1,3thiazole and 1,2,3-triazole side-chain groups, which demonstrated considerable antimicrobial activity against Gram-negative and Gram-positive bacteria and fungi. In addition, it was previously reported the potential of 1,2,3-triazoles for biofilm inhibition, ${ }^{[19,20]}$ thus these polymers can be attractive candidate to prepare antimicrobial surfaces by blending process. The hydrophobic/hydrophilic balance, the length of the alkyl chain as well as the flexibility of the polymers are factors that also importantly affect the antimicrobial efficiency. ${ }^{[14]}$ In the current work, block copolymers based on styrene and 4-(1-(2-(4-methylthiazol-5-yl)ethyl)-1H-1,2,3triazol-4-yl)butyl methacrylate (TTBM) were synthesized by simultaneous "click chemistry" and controlled radical polymerization (ATRP), and further the thiazole and triazole groups were quaternized with either methyl or butyl iodide. The copolymers were designed to have a flexible side chain ${ }^{[21]}$ with a butyl spacer to enhance the contact with the bacterial membrane. Additionally the hydrophobic/hydrophilic balance was adjusted by the presence of a long polystyrene block to maintain the copolymer water insoluble, and avoid any possible leaching out of the film. These copolymers were blending with a commercial polystyrene matrix to prepare the contact active antimicrobial film, which are of considerable interest as polystyrene is a common and versatile polymer to make a variety of consumer products, including food packaging material and biomedical items such as test tubes and petri dishes. 


\section{EXPERIMENTAL PART}

\section{Materials}

Ethyl a-bromoisobutyrate (EBriB, 98\%), copper (I) chloride (CuCl, 97\%), N,N,N',N",N'”pentamethyldiethylenetriamine (PMDETA, 99\%), iodomethane (99\%), 1-iodobutane (99\%), aluminum oxide, Trizma buffer solution $(\mathrm{pH}=7.4)$ and bovine serum albumin-fluorescein isothiocyanate conjugate (BSA-FITC), were all purchased from Aldrich and used as received. High-molecular-weight polystyrene $\left(\mathrm{PS}_{1950}, \mathrm{M}_{\mathrm{w}}=2.03 \times 10^{5} \mathrm{~g} / \mathrm{mol}, B A S F\right)$ was used as received and employed as the polymeric matrix. Styrene monomer (S, Aldrich, $\geq 99 \%$,) was purified by column chromatography (basic alumina). Polystyrene macroinitiator $\left(\mathrm{PS}_{54}, \mathrm{M}_{\mathrm{n}}=5600 \mathrm{~g} / \mathrm{mol}\right.$, $\left.M_{w} / M_{n}=1.21\right),{ }^{[22]}$ 2-(4-methylthiazol-5-yl)ethanol azide ${ }^{[18]}$ and hex-5-yn-1-yl methacrylate $(\mathrm{HMA})^{[18]}$ were synthesized following the procedure described in the literature. Anhydrous $N, N-$ dimethylformamide (DMF, Alfa Aesar,99.8\%) was used as solvent. Deuterated chloroform $\left(\mathrm{CDCl}_{3}\right)$ and dimetilsulfoxide (DMSO- $\left.\mathrm{d}_{6}\right)$ were acquired from Aldrich.

Cellulose dialysis membranes (CelluSep T1) were obtained from Membrane Filtration Products, Inc.), and round glass coverslips of $12 \mathrm{~mm}$ in diameter were supplied from Ted Pella, Inc.

In microbiological assays were used the following reactants: sodium chloride solution ( $\mathrm{NaCl}$ suitable for cell culture, BioXtra, Aldrich), phosphate buffered saline powder (PBS, pH 7.4, Aldrich), Triton $\mathrm{X}-114$ solution (for molecular biology, $\sim 10 \%$ in $\mathrm{H}_{2} \mathrm{O}$, BioUltra, Aldrich). The experiments were performed in 96-well microplates (BD Biosciences) with the aid of a Finnpipette $^{\mathrm{TM}} \mathrm{F} 2$ (Thermo Scientific) as a multichannel pipette and appropriately sized sterile pipette tips. BBL ${ }^{\mathrm{TM}}$ Mueller-Hinton broth used as a microbial growth medium was purchased from Becton, Dickinson and Company. American Type Culture Collection (ATCC): Pseudomonas aeruginosa (P. aeruginosa, ATCC 27853), Staphylococcus aureus (S. aureus, ATCC 29213), were used as bacterial strains, and the yeast Candida parapsilosis ( $C$. parapsilosis, ATCC 22109) was used as fungal strain and purchased from Oxoid.

Synthesis of PS-b-PTTBM block copolymers. 
The block copolymers were synthesized following a one-step process, simultaneous "click chemistry"/ATRP. ${ }^{[23]}$ Initially, a ratio [monomer]:[macroinitiator]:[azide]:[CuCl]:[PMDETA] = 75:1:150:1:4 was used. Briefly, PS $_{54}$ macroinitiator (1.00 g, 0.177 mmol), 2-(4-methylthiazol-5yl)ethanol azide (4.458 g, $26.52 \mathrm{mmol})$, HMA (2.203 g, $13.26 \mathrm{mmol}$ ) and PMDETA (148 $\mu \mathrm{L}$, $0.708 \mathrm{mmol}$ ) were dissolved in $8 \mathrm{~mL}$ of anhydrous DMF. The mixture was purged with argon for $30 \mathrm{~min}$ and then, $\mathrm{CuCl}(0.018 \mathrm{~g}, 0.182 \mathrm{mmol})$ was added. The solution was heated at $70 \pm 0.1$ ${ }^{\circ} \mathrm{C}$ during 6.5 hours under argon atmosphere. After that, the polymerization was stopped by exposition to air and cooling down and the mixture was purified by passing through a neutral alumina column. The copolymer was finally isolated by successive precipitation processes in acetonitrile, dried under vacuum and labeled as $\mathbf{P S}_{54}-\mathbf{b}-\mathbf{P T T B M} \mathbf{M}_{23}$ A block copolymer with longer PTTBM segment was also prepared following the same procedure but using a ratio [monomer]:[macroinitiator]:[azide]:[CuCl]:[PMDETA] = 150:1:300:1:4. This block copolymer was

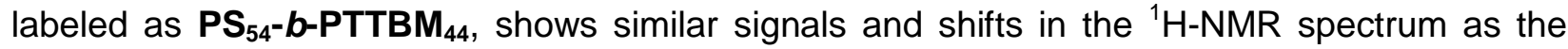
$\mathrm{PS}_{54}-b$-PTTBM 23 copolymer. ${ }^{1} \mathrm{H}-\mathrm{NMR}\left(700 \mathrm{MHz} \mathrm{CDCl}_{3}\right), \delta(\mathrm{ppm}): 8.59$ (s, $1 \mathrm{H}, \mathrm{CH}$ thiazole), 7.33 (bs, $1 \mathrm{H}, \mathrm{CH}$ triazole), 7.25-6.30 (bm, $\left.5 \mathrm{H}, \mathrm{H}_{\mathrm{Ar}} \mathrm{PS}\right), 4.55\left(\mathrm{~s}, 2 \mathrm{H}, \mathrm{OCH}_{2}\right), 3.93\left(\mathrm{bs}, 2 \mathrm{H}, \mathrm{NCH}_{2}\right), 3.39$ (s, 2H, $\mathrm{CH}_{2}$-thiazole), 2.70 (s, 2H, $\mathrm{CH}_{2}$-triazole), 2.23 (s, 3H, $\mathrm{CH}_{3}$-thiazole), 2.15-1.20 (bm, 9H, 4 $\left.\mathrm{CH}_{2}, \mathrm{CH}\right), 1.15-0.70$ (m, 3H, $\mathrm{CH}_{3}$ PTTBM). ${ }^{13} \mathrm{C}-\mathrm{NMR}$ (176 MHz, $\mathrm{CDCl}_{3}$ ) $\delta(\mathrm{ppm}):$ 178.5-176.0 (CO), 150.53 ( $\mathrm{CH}$ thiazole), 150.37 (C quat. thiazole), 147.43, 146.50-144.50 ( $\mathrm{C}_{\mathrm{Ar}}$ quat. PS), 128.50-125.00 ( $\left.\mathrm{C}_{\mathrm{Ar}} \mathrm{PS}\right), 126.18$ (=C-S quat.), $121.64\left(\mathrm{CH}\right.$ thiazole), $64.75\left(\mathrm{OCH}_{2}\right), 50.82$ $\left(\mathrm{NCH}_{2}\right), 47.00-41.00,40.37,27.68,27.57,27.37,25.94,25.10,18.55,16.63,14.69\left(\mathrm{CH}_{3}^{-}\right.$ thiazole).

\section{Quaternization reactions. Preparation of quaternized PS-b-PTTBM cationic copolymers.}

The synthesized PS-b-PTTBM copolymers were reacted with alkyl iodides, butyl or methyl iodide, to obtain the cationic polymers bearing 1,3-thiazolium and 1,2,3-triazolium groups per monomer unit. In a typical reaction, the block copolymer was dissolved in anhydrous DMF and then a large excess of alkyl iodide was added (ratio copolymer/alkyl iodide $\approx 1: 5$ ). The mixture was stirred at $80 \pm 0.1{ }^{\circ} \mathrm{C}$ for one week to ensure the complete reaction. The solution was poured into $n$-hexane and the copolymers were further purified by dialysis against distilled water 
to remove the residual products and finally were isolated by freeze-drying. The cationic copolymers quaternized with methyl iodide were labeled as $\mathbf{P S}_{54}-\boldsymbol{b}-\mathbf{P T T B M}-\mathbf{M}_{23}$ and $\mathbf{P S}_{54}-\boldsymbol{b}$ PTTBM-M $\mathbf{M}_{44}$, whereas the copolymers modified with butyl iodide were labeled as $\mathbf{P S}_{54} \mathbf{- b}$ PTTBM-B ${ }_{23}$ and PS $_{54}-b-$ PTTBM-B $_{44}$.

${ }^{1} \mathrm{H}-\mathrm{NMR}$ of $\mathrm{PS}_{54}-b-\mathrm{PTTBM}-\mathrm{M}_{23}\left(700 \mathrm{MHz}, \mathrm{DMSO}-\mathrm{d}_{6}\right), \delta$ (ppm): 10.09 (s, $1 \mathrm{H}, \mathrm{CH}$ thiazolium), 8.89 (bs, $1 \mathrm{H}, \mathrm{CH}$ triazolium), 7.30-6.25 (m, 5H, $\left.\mathrm{H}_{\mathrm{Ar}} \mathrm{PS}\right), 4.90$ (bs, $3 \mathrm{H},{ }^{+} \mathrm{NCH}_{3}$ triazolium), 4.29 (s, $3 \mathrm{H},{ }^{+} \mathrm{NCH}_{3}$ thiazolium), $4.11\left(\mathrm{~s}, 2 \mathrm{H}, \mathrm{OCH}_{2}\right), 3.70\left(\mathrm{~s}, 2 \mathrm{H}, \mathrm{NCH}_{2}\right), 3.35\left(\mathrm{bs}, 2 \mathrm{H}, \mathrm{CH}_{2}\right.$-thiazolium), 2.98 (bs, 2H, $\mathrm{CH}_{2}$-triazolium), 2.51 (s, 2H, $\mathrm{CH}_{3}$-thiazolium), 2.25-0.50 (bm, 12H, 4CH, $\mathrm{CH}$, $\left.\mathrm{CH}_{3}\right)$.

${ }^{13} \mathrm{C}$ NMR (176 MHz, DMSO-d $\left.\mathrm{d}_{6}\right) \delta(\mathrm{ppm}):$ 178.5-176.0 (CO), 158.30 (CH thiazolium), 144.80, $144.45,131.84\left(\mathrm{CH}\right.$ triazolium), 129.38, 128.39, 127.66, 126.09, 64.82( $\left(\mathrm{OCH}_{2}\right), 53.23\left(\mathrm{NCH}_{2}\right)$, 45.12 (C quat.) $41.44\left(2 \mathrm{CH}_{3} \mathrm{~N}^{+}\right), 28.95,27.83,26.5823 .55,20.00-14.50\left(\mathrm{CH}_{3}\right), 12.66\left(\mathrm{CH}_{3}^{-}\right.$ thiazolium).

${ }^{1} \mathrm{H}-\mathrm{NMR}$ of $\mathrm{PS}_{54}-b-\mathrm{PTTBM}-\mathrm{B}_{23}\left(700 \mathrm{MHz}, \mathrm{DMSO}-\mathrm{d}_{6}\right), \delta(\mathrm{ppm}): 10.18$ (s, $1 \mathrm{H}, \mathrm{CH}$ thiazolium), 9.16 (bs, $1 \mathrm{H}, \mathrm{CH}$ triazolium), 7.3.-6.25 (m, 5H, $\left.\mathrm{H}_{\mathrm{Ar}} \mathrm{PS}\right), 4.95$ (bs, $2 \mathrm{H},{ }^{+} \mathrm{NCH}_{2}$ triazolium), 4.804.45 (bm, 4H, $\mathrm{OCH}_{2}{ }^{+} \mathrm{NCH}_{2}$ thiazolium), 3.78 (s, $2 \mathrm{H}, \mathrm{NCH}_{2}$ ), 3.59 (bs, $2 \mathrm{H}, \mathrm{CH}_{2}$-thiazolium), 3.05 (bs, 2H, CH -triazolium), 2.51 (s, 2H, $\mathrm{CH}_{3}$-thiazolium), 2.25-1.20 (m, $\left.21 \mathrm{H}, 10 \mathrm{CH}_{2}, \mathrm{CH}\right), 0.92$ (bs, $9 \mathrm{H}, 3 \mathrm{CH}_{3}$ ).

${ }^{13} \mathrm{C}$ NMR (176 MHz, DMSO-d $\left.\mathrm{d}_{6}\right) \delta(\mathrm{ppm}):$ 180.0-175.0 (CO), 157.76 (CH thiazolium), 144.28, $132.48(\mathrm{CH}$ triazolium $), 129.48,128.41,127.66,126.11,65.00\left(\mathrm{OCH}_{2}\right), 53.49\left(2{ }^{+} \mathrm{NCH}_{2}\right), 51.25$ $\left(\mathrm{NCH}_{2}\right), 45.15$ (C quat.) 31.28, 30.51, 29.48, 27.41, 26.44, 25.96, 23.71, 24.50-22.00, 19.91, 19.43, $13.97\left(2 \mathrm{CH}_{3}\right), 12.44\left(\mathrm{CH}_{3}\right)$. 


\section{Polymer Characterization}

${ }^{1} \mathrm{H}$ and ${ }^{13} \mathrm{C}$ Nuclear Magnetic Resonance (NMR) measurements were carried out at room temperature with a Bruker AVIII spectrometer (700 MHz for ${ }^{1} \mathrm{H}$ and $176 \mathrm{MHz}$ for $\left.{ }^{13} \mathrm{C}\right)$ using as solvents $\mathrm{CDCl}_{3}$ and DMSO- $\mathrm{d}_{6}$ purchased from Sigma-Aldrich. All chemical shifts are reported in ppm $(\delta)$ referenced to the chemical shifts of residual solvent resonances. Molecular weights and polydispersity indexes of block copolymers were determined by gel permeation chromatography (GPC) on Waters Division Millipore system and a Waters 2414 refractive index detector, with 1 $\mathrm{mL} / \mathrm{min}$ flow rate of DMF (GPC grade stabilized with $0.1 \mathrm{M} \mathrm{LiBr}$, Scharlau) as eluent at $50{ }^{\circ} \mathrm{C}$. The calibration was made with poly (methyl methacrylate) standards (Polymer Laboratories LTD).

\section{Film preparation}

Films of $12 \mathrm{~mm}$ in diameter were performed by spin-coating on round glass slides from blends of block copolymers with commercial high-molecular weight polystyrene matrix, $\mathrm{PS}_{1950}$, in ratios of $0,10,30,50$ and $100 \% \mathrm{w} / \mathrm{w}$ in a $7 \% \mathrm{w} / \mathrm{v}$ DMF solution. After the spin-coating, the samples were dried at room temperature and no special treatment was performed.

\section{Surface characterization}

Water contact angle measurements were performed in a KSV Theta goniometer from digital images of $3.0 \mu \mathrm{L}$ water droplets on the surface. All the samples were tested in triplicate and the average value \pm SD (standard deviation) are presented.

The surface topography of the prepared films was analyzed by means of atomic force microscopy (AFM) measurements conducted on a Multimode Nanoscope IVa, Digital Instrument/Veeco operated in tapping mode under ambient conditions. Scanning electron microscopy (SEM) images of the surfaces were also performed using a Philips XL30 with an acceleration voltage of $25 \mathrm{kV}$. The samples were coated with gold-palladium (80/20) prior to scanning. 


\section{Protein adsorption experiments}

The prepared films (12 $\mathrm{mm}$ of diameter) were immersed in $0.5 \mathrm{~mL}$ of the BSA-FITC solution (1 $\mathrm{mg} \mathrm{mL}^{-1}, \mathrm{pH}=7.4$ in Trizma solution), which was freshly prepared prior to use. The films were incubated for $3 \mathrm{~h}$ and $24 \mathrm{~h}$ at $25 \stackrel{\circ}{\circ}$ and then were taken out from the solution. The resultant solutions with unbound protein were then analyzed. Briefly, $100 \mu \mathrm{L}$ of each solution were placed in a 96-well round-bottom microplate and $100 \mu \mathrm{L}$ of Trizma solution were added to each well. All the samples were analyzed in triplicate and blank experiments were carried out with $200 \mu \mathrm{L}$ of Trizma solution. The fluorescence intensity of each well was measured using a Synergy HTX Multi-Mode Reader spectrophotometer (Bio-Tek) at an excitation wavelength of $480 \mathrm{~nm}$ and at an emission wavelength of $525 \mathrm{~nm}$. The data were converted to concentration of unbound protein using the corresponding standard curve and the protein adsorbed onto the surface was estimated by subtracting the unbound concentration from the initial concentration.

\section{Evaluation of antimicrobial activity in films}

Antimicrobial activities of the films prepared by spin coating were determined following the E2149-01 standard method from the American Society for Testing and Materials (ASTM) ${ }^{[24]}$ with minor modifications. The microorganisms $S$. aureus, $P$. aeruginosa and $C$. parapsilosis were all grown on $5 \%$ sheep blood Columbia agar plates for $24 \mathrm{~h}$ for bacteria and 48 for fungi in an incubator at $37^{\circ} \mathrm{C}$ (Jouan IQ050 incubator). Then, the concentration was adjusted with saline solution to a turbidity equivalent of $0.5-1$ McFarland turbidity standard $\left(1-3 \times 10^{8}\right.$ colony forming units $(\mathrm{CFU}) / \mathrm{mL})$. The optical density of the microorganism suspension was measured in a DensiCHEKTM Plus (VITEK, bioMérieux). This suspension was further diluted (1:100) with Mueller-Hinton broth to yield the working solution $\left(10^{6} \mathrm{CFU} / \mathrm{mL}\right)$. Each film was placed in a sterile falcon tube and then $10 \mathrm{~mL}$ of the tested inoculum were added. As control experiments, tubes with commercial PS $_{1950}$ film and with only inoculum were also prepared. The samples were shaken at $120 \mathrm{rpm}$ during $24 \mathrm{~h}$. After that, $1 \mathrm{~mL}$ of solution from each tube was serially diluted, placed on $5 \%$ sheep blood Columbia agar plates and incubated as described before to 
determine bacterial counts by plate count method. The measurements were made at least in triplicate.

\section{RESULTS AND DISCUSSION}

\section{Antimicrobial amphiphilic block copolymers synthesis and characterization}

Scheme 1 illustrates the synthetic approach used for the synthesis of the cationic copolymers. The preparation of the antimicrobial copolymers was carried out by combination of ATRP and copper-catalyzed azide-alkyne cicloaddition (CuAAC) click reaction to obtain well-defined copolymers, followed by a quaternization step. ${ }^{[23]}$ TTBM monomer is synthesized by click chemistry between HMA and 2-(4-methylthiazol-5-yl)ethanol azide using CuCl/PMDETA as catalyst system. Simultaneously, this monomer TTBM is polymerized with the same catalyst via ATRP from PS macroinitiator, leading the $\mathrm{PS}_{54^{-}} b-\mathrm{PTTBM}_{n}$.

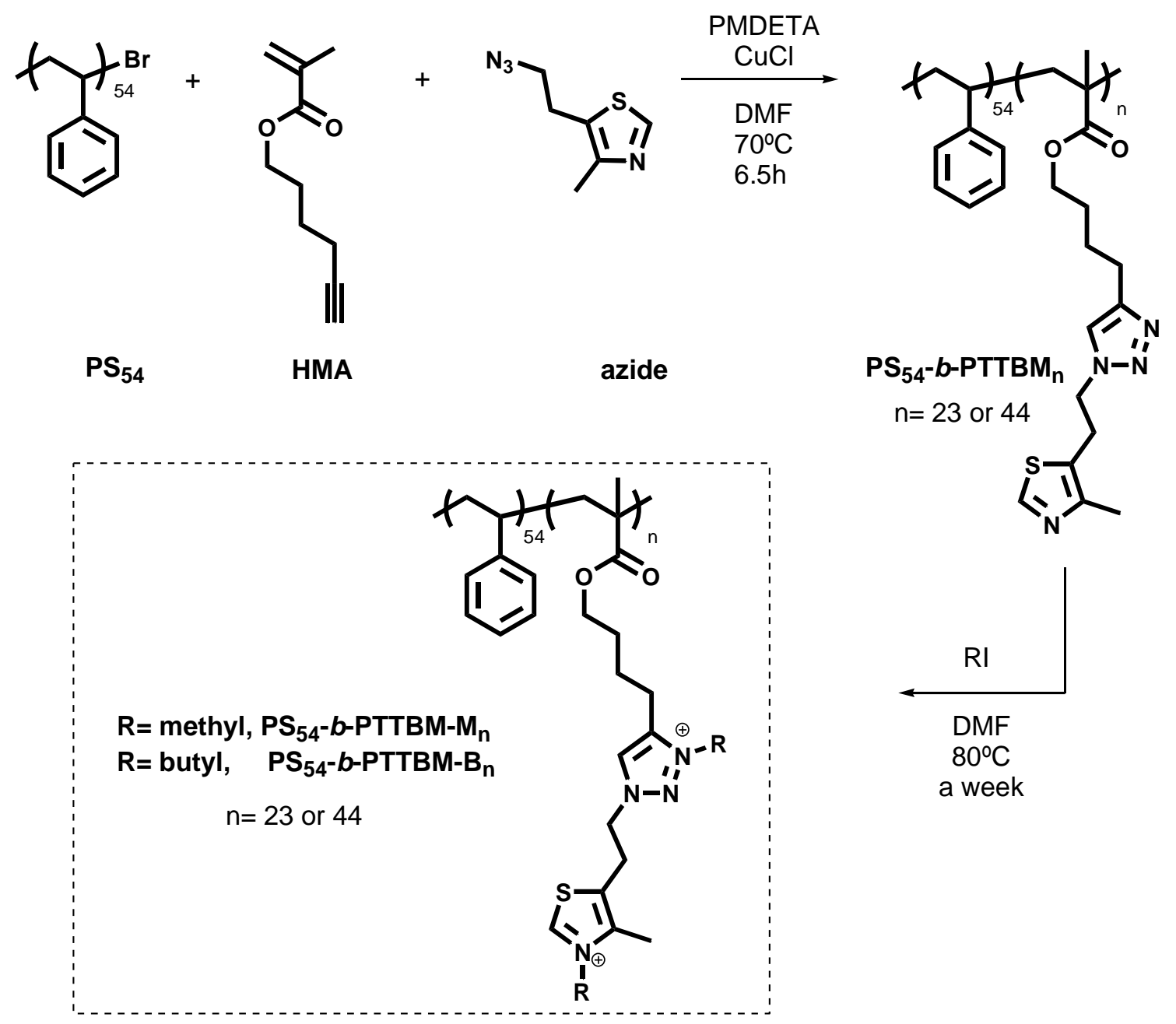


Scheme 1. Schematic representation of antimicrobial block copolymer synthesis by combination of ATRP and CuAAC click reaction, followed by a quaternization step.

This one-pot ATRP/CuAAC reaction were performed using a [macroinitiator]:[CuCl]:[PMDETA] ratio of 1:1:4 for all reactions, while the [HMA]:[azide]:[macroinitiator] ratio was varied in order to obtain copolymers with different composition, $75: 150: 1$ and 150:300:1 for the preparation of $\mathrm{PS}_{54}-b-\mathrm{PTTBM}_{23}$ and $\mathrm{PS}_{54}-b-\mathrm{PTTBM}_{44}$, respectively. The reactions were monitored by ${ }^{1} \mathrm{H}-\mathrm{NMR}$, taking samples of the reaction mixture at set time intervals. It was appreciated the signals corresponding to the protons of thiazole rings at the beginning of the reaction, which indicates that 'click' reaction is almost instantaneously completed, whereas the vinyl signals at ca. 6.0 and $5.5 \mathrm{ppm}$ decrease continuously during the course of the polymerization.ref After $6.5 \mathrm{~h}$ the reaction was stopped and the TTBM monomer conversion was determined before purification, using relative intensity of the signals from the vinyl protons (6.0 and $5.5 \mathrm{ppm})$ and $\alpha$-methyl hydrogens of the polymer ( 1.1-0.5 ppm), resulting $\sim 30 \%$ in both cases. This is expected because the reactions were carried out using similar reaction time.ref Then, the resulting block copolymers after purification were also characterized by gel permeation chromatography (GPC) and ${ }^{1} \mathrm{H}$ and ${ }^{13} \mathrm{C}-\mathrm{NMR}$ (see Figure $\mathrm{S} 1$ of Supporting Information). The composition of the obtained copolymer was determined by using the signal at $4.11 \mathrm{ppm}\left(\mathrm{OCH}_{2}\right)$ of the PTTBM and the aromatic signal of PS (7.2-6.2 ppm). The yield of the reactions calculated gravimetrically was found to be $87 \%$ and $83 \%$ for the $\mathrm{PS}_{54}-b-\mathrm{PTTBM}_{23}$ and $\mathrm{PS}_{54}-b-\mathrm{PTTBM}_{44}$ copolymers, respectively. The number-average molecular weights estimated by ${ }^{1} \mathrm{H}-\mathrm{NMR}$ and GPC and the polydispersity indices obtained from GPC are collected in Table 1 (GPC curves are shown in Figure S2). However, only the molecular weights calculated by NMR were considered because the GPC measurements have been performed against PMMA standards, therefore these values can be over or underestimated.

Table 1. Number average molecular weight, $M_{n}$, obtained by GPC and calculated by ${ }^{1} \mathrm{H}-\mathrm{NMR}$ and polydispersity index, PDI, of copolymers $\mathrm{PS}_{54}-b-\mathrm{PTTBM}_{\mathrm{n}}$. 


\begin{tabular}{|c|c|c|c|c|}
\hline Copolymer & [PS]:[MTA] & $M_{n}^{N M R}(g / m o l)$ & $M_{n}{ }^{G P C}(g / m o l)$ & PDI \\
\hline $\mathrm{PS}_{54}-b-\mathrm{PTTBM} \mathrm{T}_{23}$ & $1: 75$ & 13600 & 32300 & 1.74 \\
\hline $\mathrm{PS}_{54}-b-\mathrm{PTTBM} 44$ & $1: 150$ & 22000 & 46700 & 1.53 \\
\hline
\end{tabular}

Next, both copolymers were quaternized to introduce cationic charge in their structures and increase their activity against pathogens. ${ }^{[14]}$ These copolymers contain TTBM units bearing a thiazole and a triazole per monomeric units, both groups susceptible of quaternization. Consequently, the resulting dicationic copolymers would present high charge density, bearing both 1,3-thiazolium and 1,2,3-triazolium groups. The reactions were carried out employing two alkylation agents, iodomethane and 1-iodobutane, in order to study the influence hydrophobic character of the alkyl group in the activity. The hydrophobic/hydrophilic balance is a crucial factor, as more hydrophobic chains interact better with the bacterial membrane, improving the bactericidal action. In contrast, high hydrophobicity significantly reduces the polymer solubility, which is important for the use of antimicrobial agents in solution but it may be beneficial for their use in surfaces. The quaternization process was performed in DMF at $80 \stackrel{\circ}{\mathrm{C}}$ using a great excess of alkylation agent to assure the complete quaternization. The obtained copolymers were named as PS- $b$-PTTBM-M and PS- $b$-PTTBM-B, for the iodomethane and 1-iodobutane quaternization, respectively. In effect, ${ }^{1} \mathrm{H}-\mathrm{NMR}$ spectroscopy confirms that all modifications were achieved quantitatively. Figures S3 and S4 of the Supporting Information show that the signals assigned to the aromatic protons of the 1,3-thiazole and 1,2,3-triazole rings $(=\mathrm{CH}$ of 1,3 -thiazole around $8.59 \mathrm{ppm}$ and $=\mathrm{CH}$ of 1,2,3-triazole around $7.33 \mathrm{ppm}$ ) disappear and new bands corresponding to the thiazolium and triazolium rings are observed at higher $\delta$ shifts $(=\mathrm{CH}$ of $1,3-$ thiazolium ring around $10.09 \mathrm{ppm}$ and $=\mathrm{CH}$ of 1,2,3-triazolium ring around $8.89 \mathrm{ppm}$ ). The resulting copolymers were not water soluble, due to the shorter PTTBM segment with respect to the hydrophobic PS block. In addition, TTBM monomer presents a longer spacer in comparison with others monomers with analogous structures previously used for the synthesis of antimicrobial polymers, thus its water solubility is reduced. ${ }^{[21]}$ This fact is important as these 
copolymers will be used in surfaces to introduce antimicrobial activity, therefore we can avoid or reduce diffusion problems to the aqueous media.

\section{Antimicrobial films preparation and surface characterization}

Several films were prepared from the resulting cationic copolymers by blending these copolymers with commercial high molecular weight polystyrene in different proportions ([copolymer]/[PS]:10, 30, 50 and 100 wt.\%). Both components were dissolved in DMF (7 \%w/v) and films were prepared by spin-coating over glass coverslips of $12 \mathrm{~mm}$ of diameter. This is a simple method to prepare functional films by incorporating relatively low content of active copolymer into a low-cost matrix, without the need of employing multiples chemical reactions, which are usually required in other approaches.

Before evaluating the antimicrobial ability of these antimicrobial films, their surface properties were analyzed. Contact angle measurements were carried out to study the water wettability of the prepared films and evaluate the hydrophobicity of the surfaces. Remarkably, Figure 1 reveals for all the series of samples that the blend films ([copolymer]/[PS]:10, 30, $50 \mathrm{wt} . \%$ ) exhibit higher contact angle values than the films obtained by the individual components, either PS (0 wt. \% of antimicrobial copolymer) or the copolymer (100 wt.\%). Furthermore, the blends containing the copolymers with the longest segment of PTTBM (degree of polymerization $=44$ ) presented higher values that those with the copolymer with only 23 units of antimicrobial content. When the alkylating agent is compared, butyl and methyl, a difference in contact angle is also appreciated, presenting higher contact angles the films containing the copolymer quaternized with butyl in the case of the copolymers with the longest PTTBM segment. Unexpected, films with the $\mathrm{PS}_{54}-b$-PTTBM-M $\mathrm{M}_{23}$ copolymer exhibit lower contact angle values than the corresponding $\mathrm{PS}_{54}-b-\mathrm{PTTBM}-\mathrm{B}_{23}$. 


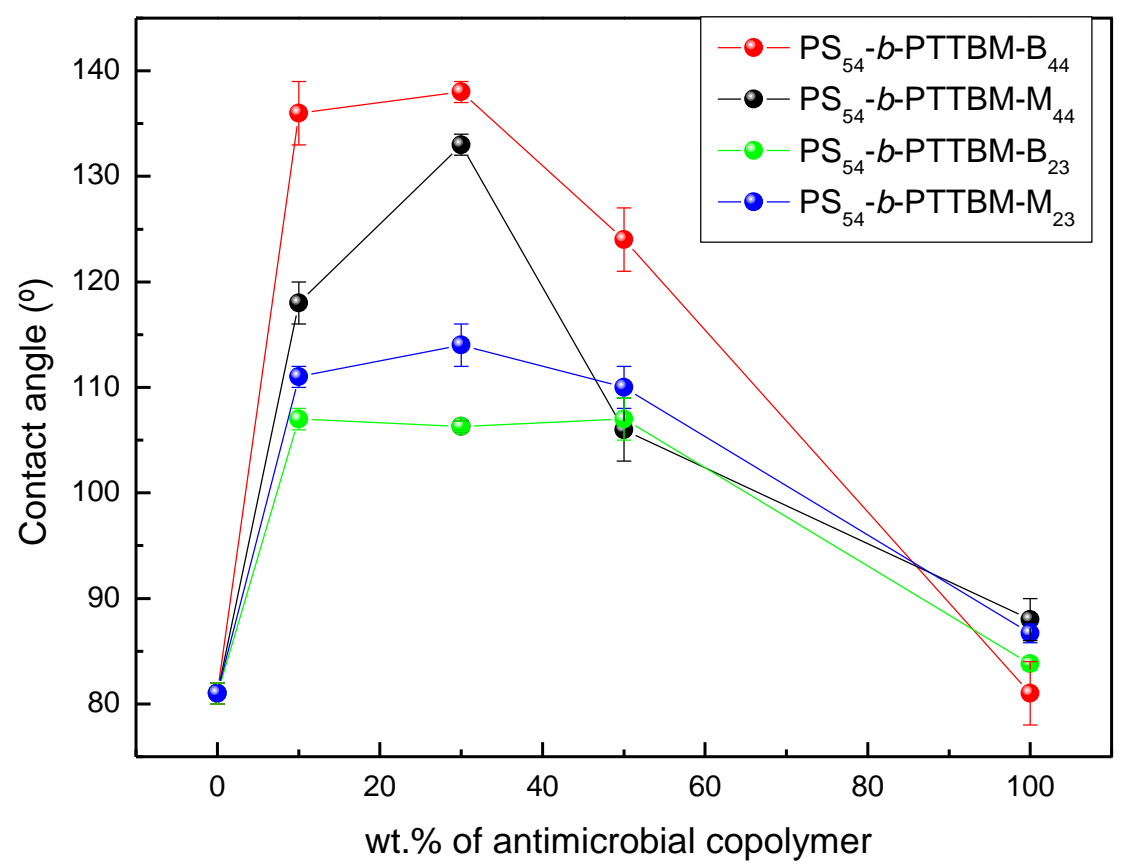

Figure 1. Water contact angle values of the films composed of the different blends as a function of the content of antimicrobial copolymer in the blend.

It is well known that, in addition to the chemical composition of the surface, the roughness plays an important role in the contact angle values and it seems from these results that the type and the content of the copolymer in the blend could also modify the surface topography of the films. Next, the surface topography of the obtained surfaces was studied by SEM and AFM. Figure 2 shows the SEM micrographs of the films prepared from the blends with the PS ${ }_{54}-b-\mathrm{PTTBM}-\mathrm{M}_{23}$ copolymer. 


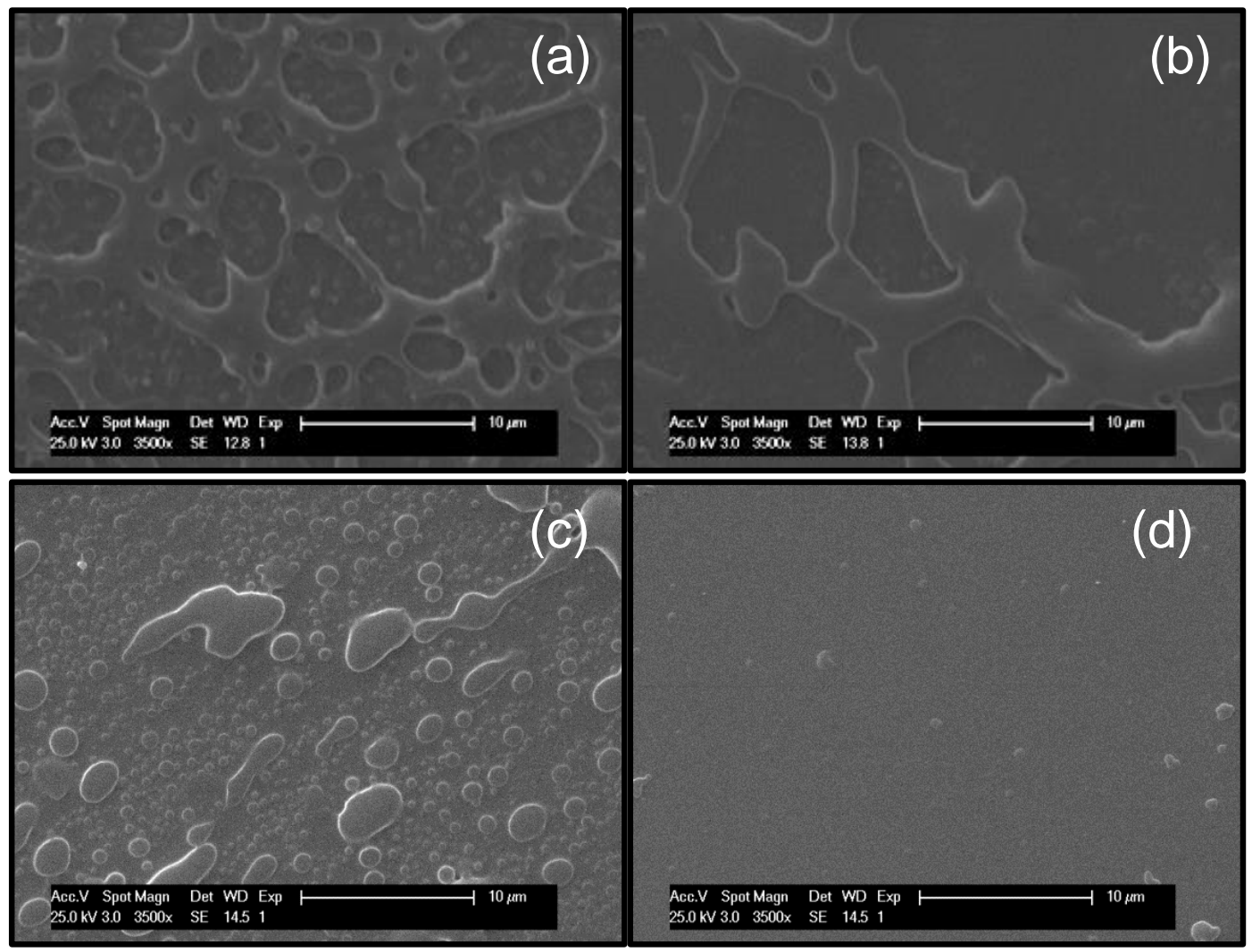

Figure 2. SEM images of the films composed of different blends, $P S_{54}-b-P T T B M-M_{23} / P S$ : a) $10 / 90$, b) $30 / 70$, c) 50/50 and d) $100 / 0$ wt. \%.

It is clearly appreciated that the surfaces obtained for blends are significantly rough in comparison with the films prepared from either the copolymer alone, PS $54-b-\mathrm{PTTBM}-\mathrm{M}_{23} /$ PS:100/0 wt.\%, or polystyrene alone, $\mathrm{PS}_{54}-b-\mathrm{PTTBM}_{23} / \mathrm{PS}:$ 0/100 wt,\% (image non shown). This behavior is observed in all the films prepared from the rest of the copolymers, $\mathrm{PS}_{54}-b$ PTTBM- $B_{23}$, PS $_{54}-b-P T T B M-M_{44}$ and PS $_{54}-b-P_{T T B M-B_{44}}$. Figure S5 of the Supporting information shows the SEM images of the films containing 50 wt.\% of the antimicrobial copolymer, in which the high roughness of the surfaces is observed. The sample composed of $50 \mathrm{wt} . \%$ of $\mathrm{PS}_{54}-b$ PTTBM- $B_{23}$ exhibits, however, a more homogeneous surface, fact that can explain the lower contact angle values found. The surface roughness is probably due to a phase separation process as a consequence of the incompatibility of the different blend components. ${ }^{[25]}$ The surface morphology of the prepared films was further examined by AFM, as depicted in Figure 3 
for the sample containing $10 \mathrm{wt} \%$ of $\mathrm{PS}_{54}-\mathrm{b}-\mathrm{PTTBM}-\mathrm{M}_{44}$. The topography images show that the surfaces have both micro and nano-roughness, which increase significantly the surface area of the antimicrobial films.
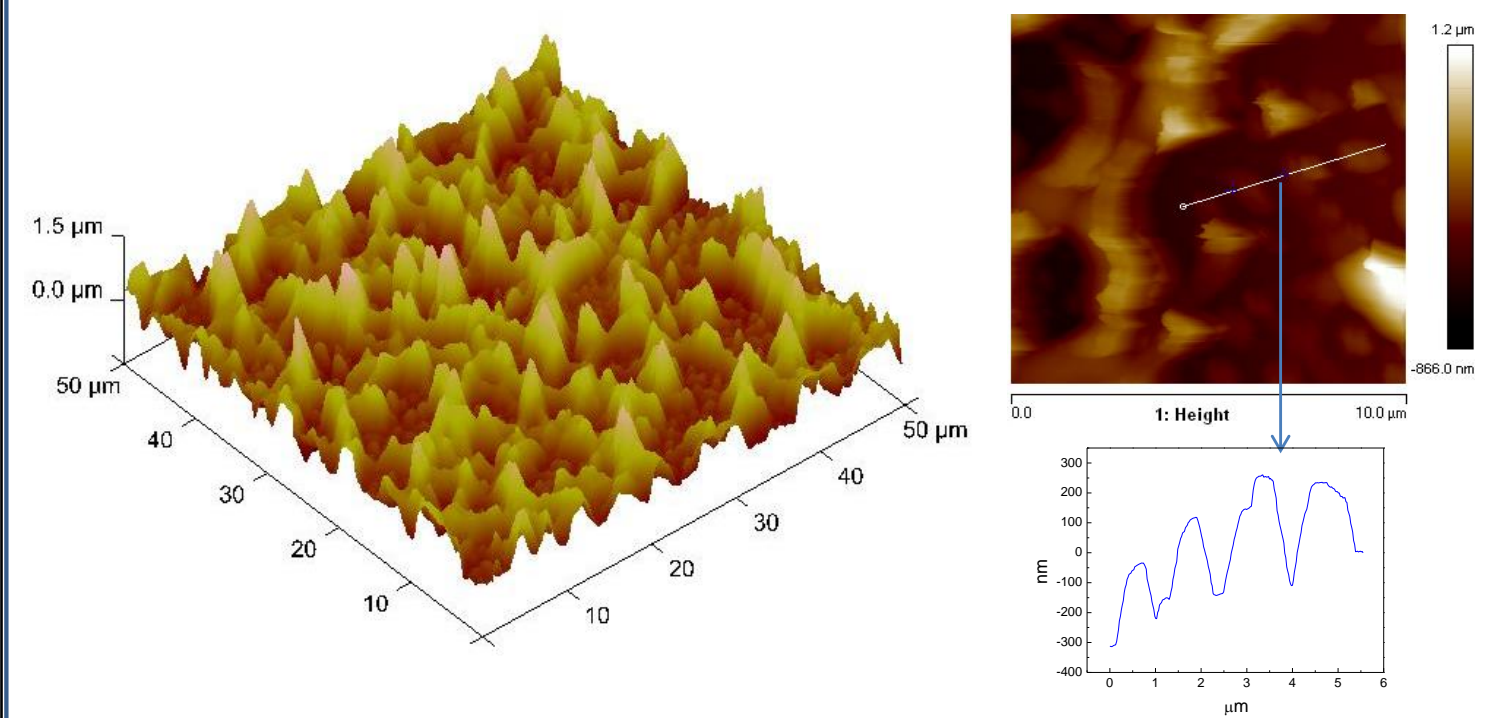

Figure 3. AFM topographic images and cross section height curve for the film composed of PS ${ }_{54}-b-P T T B M-M_{44} /$ PS: 10/90.

This surface roughness found in the prepared blend films can explain the higher contact angle values obtained in blends in comparison with the values found in the films formed only by one component. This is of great importance because the roughness as well as the chemical composition can significantly govern the action of active contact antimicrobial films, as the surface area increases with nano and micro-roughness and, therefore, the number of active groups. In fact, it has been previously reported that roughness can enhance contact-active antibacterial activities. ${ }^{[26,27]}$ 


\section{Protein adsorption experiments}

Although there is still a lack of complete understanding of the antimicrobial mechanisms of action of polycations, it is generally accepted that the surfaces tethered polycations can disrupt the integrity of the microbial membrane through electrostatic interactions. Meanwhile, the hydrophobic alkyl chains of polycations can intercalate into the bilayer structure causing holes in the membrane. ${ }^{[28-31]}$ Nevertheless, the bacterial cells need to be previously adsorbed on the surface to induce their death. Then, the content of the cationic copolymers at these rough surfaces and their surface accessibility was then studied. For this purpose, protein adsorption experiments were performed using BSA as a model protein, which presents negative net charge at neutral $\mathrm{pH}$ and is able to adsorb onto the surface through electrostatic interactions. The prepared films were immersed into a FITC-labeled BSA solution for $3 \mathrm{~h}$ and $24 \mathrm{~h}$. The protein adsorbed onto the surfaces was quantified by analyzing the unbound protein of the resultant solutions by fluorescence spectroscopy. Figure 4 shows the results obtained for all the films prepared from the blends. 

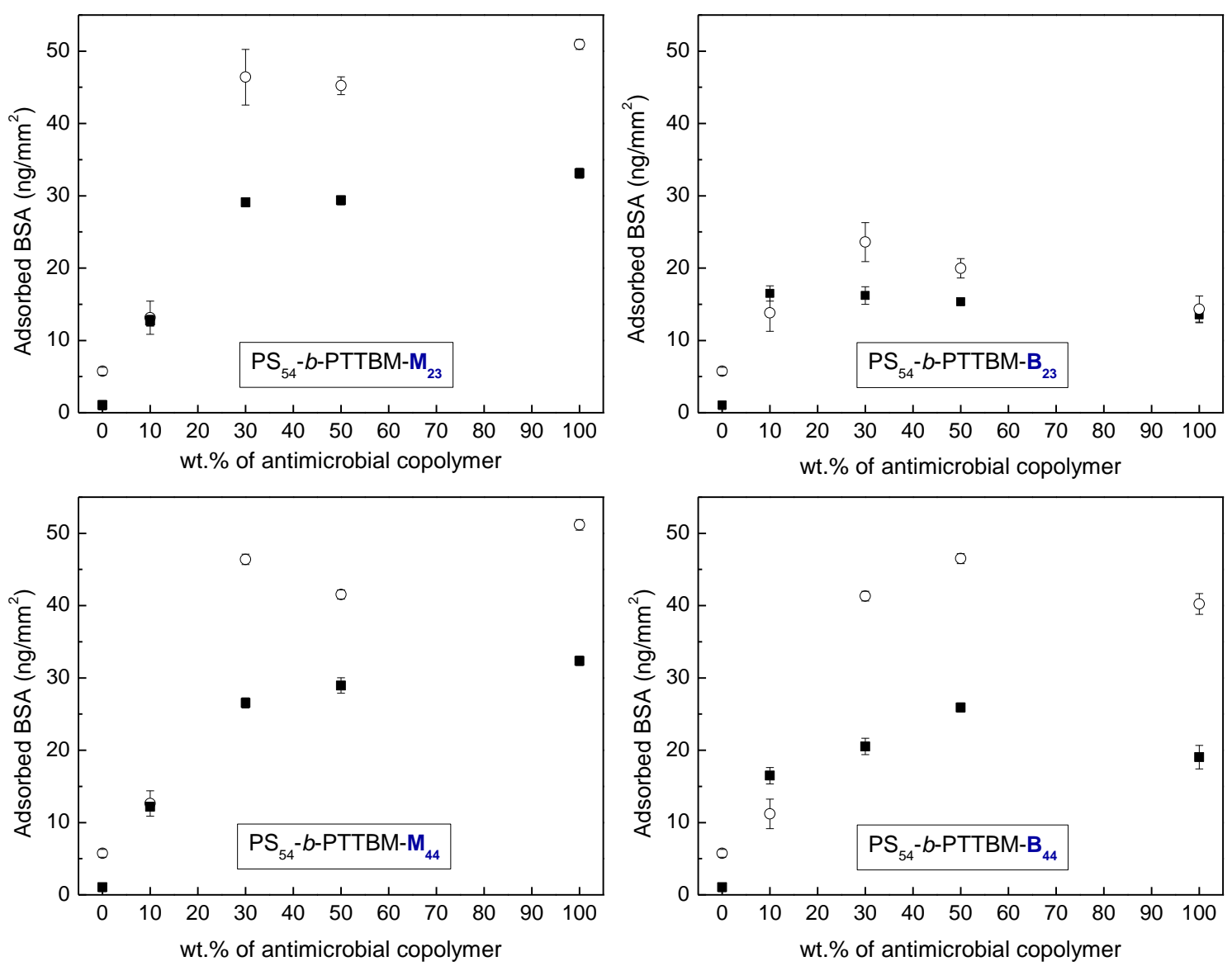

Figure 4. Amount of BSA adsorbed per $\mathrm{mm}^{2}$ onto the surfaces prepared from the cationic copolymers after incubation in BSA solution for $(\bullet) 3 h$ (०) $24 h$.

Figure 4 shows that the amount of BSA adsorbed per $\mathrm{mm}^{2}$ augments as the content of the cationic copolymer increases in the blend up to $30-50 \mathrm{wt} \%$. Interestingly in all the cases, the films composed of $30-50$ wt.\% of copolymer exhibit practically similar adsorption as the film formed with $100 \mathrm{wt} \%$ of copolymer. This seems to indicate that although the blends present a lesser content of copolymer, the cationic groups are highly accessible for electrostatic interaction probably because the greater surface area found in these films. Another interesting remark observed in the graphs is that the adsorption does not increase from $3 \mathrm{~h}$ to $24 \mathrm{~h}$ of incubation in the case of blends with lower content of copolymer, which indicates that saturation has been reached. However, in films with 30, 50 and 100 wt.\% of copolymer, the amount of protein adsorbed on the surface augments at $24 \mathrm{~h}$ of incubation with values near $50 \mathrm{ng} / \mathrm{mm}^{2}$, meaning 
more accessible cationic moieties in these films. It is noteworthy to mention, that the films containing the copolymer $\mathrm{PS}_{54}-b-\mathrm{PTTBM}-\mathrm{B}_{23}$ are able to adsorbed much lesser amount of protein. This is the copolymer with the shortest cationic segment and quaternized with butyl iodine, accordingly the most hydrophobic copolymer of the synthesized series.

\section{Antimicrobial activity study}

The antimicrobial activity of the prepared films was tested using Gram-positive and Gramnegative bacteria, and fungi, namely, $S$. aureus, $P$. aeruginosa and $C$. parapsilosis, respectively. Concretely, the bactericidal activity was studied by a shake flask test according to ASTM E2149-01. ${ }^{[24]}$ This is a quantitative antibacterial test method for determining the antibacterial activity of non-leaching antibacterial surfaces under dynamic contact conditions. An exclusively contact killing mechanism is expected because the antimicrobial copolymers used in the blends are not water-soluble and therefore their leaching and diffusion from the films might be limited.

Table 2 summaries the cell killing percentage expressed with respect to control experiments in which the bacterial reduction was null (experiments performed with films prepared from commercial PS, 0 wt.\% of copolymers, and without any films). From the results, it can be seen that in general, the films are more effective against Gram-positive $S$. aureus than against Gramnegative $P$. aeruginosa. This is because Gram-positive and Gram-negative bacteria possess different envelope structure. While Gram-positive bacteria have a loosely packed polyglycane cell wall, Gram-negative bacteria present an additional membrane composed of a phospholipids bilayer, that makes more difficult the penetration of the antimicrobial chains, increasing their resistance. ${ }^{[16],[32]}$ Remarkably, the blend films containing $\mathrm{PS}_{54}-b-\mathrm{PTTBM}-\mathrm{M}_{23}, \mathrm{PS}_{54}-b-\mathrm{PTTBM}-\mathrm{M}_{44}$ and $\mathrm{PS}_{54}-b$-PTTBM-B 44 copolymers possess excellent killing efficiencies against $S$. aureus, exhibiting reductions of more than $99.999 \%$ in the most of the cases. In contrast, the films composed of the copolymer $\mathrm{PS}_{54}-b-\mathrm{PTTBM}-\mathrm{B}_{23}$ present moderate activity against $S$. aureus, only the film with 50 wt.\% of copolymer exhibit significant efficiency, $99 \%$ of reduction. This is in concordance with the protein adsorption experiments, in which it was observed that the films obtained from this copolymer, $\mathrm{PS}_{54}-b-\mathrm{PTTBM}-\mathrm{B}_{23}$, adsorbed smaller amount of protein in comparison with the rest of the samples. Thus, it can be said that probably the quaternary 
ammonium groups are less accessible and/or less effective in disrupting the bacterial membrane, as the PTTBM-B segment is short and the alkylating agent is butyl iodine. Apart from these films with low activity, the rest of the samples show excellent activity, as commented. The cell killing efficiencies are higher than previous studies in antimicrobial blend films composed of very similar copolymers. ${ }^{[22]}$ In that work, the copolymer also consisted of PS segment and a methacrylic block containing triazole and thiazole groups, which were quaternized with butyl iodide. This quaternized block had more rigid side chain ${ }^{[21]}$ than the PTTBM block used in the current study. Chain mobility is also an important factor for successful membrane disruption, as the cationic charge along flexible chain could better interact simultaneously with the bacterial membrane through multiple interactions. ${ }^{[33]}$

More interesting is the statement, as a general trend, the blends present better activity than the films obtained from 100 wt.\% of cationic copolymers. This fact, in principle, is unexpected because the blends have less content of antimicrobial cationic copolymer. This greater efficiency could be explained by two factors. On one hand, the cationic copolymer could readily migrate to the surfaces of blend films, and then the chemical composition of the blend might be nearly to that of the films with 100 wt.\% of copolymer. On the other hand, the higher roughness that is found in the blend films, mainly in the blends containing 50 wt.\% of copolymer, conducts to higher surface area able to contact with the microorganisms. 
Table 2. Chemical composition of the antimicrobial films and their microorganism elimination effectiveness.

\begin{tabular}{|c|c|c|c|c|}
\hline & Blends & S. aureus & P. aeruginosa & C. parapsilosis \\
\hline Block copolymer & PS/copolymer & \multicolumn{3}{|c|}{ Cell killing (\%) } \\
\hline $\mathrm{PS}_{54}-b-\mathrm{PTTBM}-\mathrm{M}_{23}$ & $\begin{array}{l}90 / 10 \\
70 / 30 \\
50 / 50 \\
0 / 100\end{array}$ & $\begin{array}{c}99 \\
99.999 \\
99.999 \\
99.9\end{array}$ & $\begin{array}{c}78 \\
78 \\
99.999 \\
75\end{array}$ & $\begin{array}{c}67 \\
92 \\
99.999 \\
90\end{array}$ \\
\hline $\mathrm{PS}_{54}-b-\mathrm{PTTBM}-\mathrm{M}_{44}$ & $\begin{array}{l}90 / 10 \\
70 / 30 \\
50 / 50 \\
0 / 100\end{array}$ & $\begin{array}{c}99.999 \\
99.999 \\
99.999 \\
97\end{array}$ & $\begin{array}{c}72 \\
97 \\
99.9 \\
76\end{array}$ & $\begin{array}{c}93 \\
99.999 \\
99.999 \\
90\end{array}$ \\
\hline $\mathrm{PS}_{54}-b-\mathrm{PTTBM}-\mathrm{B}_{23}$ & $\begin{array}{l}90 / 10 \\
70 / 30 \\
50 / 50 \\
0 / 100\end{array}$ & $\begin{array}{l}90 \\
98 \\
99 \\
93\end{array}$ & $\begin{array}{l}70 \\
87 \\
78 \\
78\end{array}$ & $\begin{array}{l}67 \\
70 \\
70 \\
83\end{array}$ \\
\hline $\mathrm{PS}_{54}-b-\mathrm{PTTBM}-\mathrm{B}_{44}$ & $\begin{array}{l}90 / 10 \\
70 / 30 \\
50 / 50 \\
0 / 100\end{array}$ & $\begin{array}{c}99.999 \\
99.999 \\
99.999 \\
99.9\end{array}$ & $\begin{array}{l}78 \\
78 \\
97 \\
78\end{array}$ & $\begin{array}{l}67 \\
90 \\
98 \\
50\end{array}$ \\
\hline
\end{tabular}

Especially active are the blends containing the copolymers with methyl alkyl chains, with a more than $99.99 \%$ killing efficiency also against $P$. aeruginosa Gram-negative bacterium and C. parapsilosis fungus. From the microbial analysis results, we can infer several conclusions. First, films prepared from the cationic copolymers exhibit excellent antibacterial activity against $S$. aureus, with the exception of the copolymer with shorter cationic block and with butyl as alkyl chain. The efficiency is moderate, however, against Gram-negative $P$. aeruginosa and $C$. 
parapsilosis fungus. Secondly, the films containing the copolymers with methyl as alkyl chain seems to present better activities than their homologues with butyl. And more important, blend films, in particular those containing 50 wt\%, shows significant killing efficiencies, even higher than the films composed exclusively from the corresponding cationic copolymers.

\section{Conclusions}

In summary, a series of contact active antimicrobial films were prepared by simple spin-coating of cationic copolymers containing TTBM units and their blends with commercial polystyrene. The synthesized copolymers contain cationic blocks with two quaternary ammonium group per monomer that confer high cationic charges, and a flexible lateral chain which provides mobility and accessibility for a adequate contact killing performance. The blends films, in particular those with 30 and 50 wt.\% of cationic copolymer in the blend, exhibit significant antimicrobial activities against Gram-positive, Gram-negative bacteria and fungi, with a more than $99.99 \%$ killing efficiency in most of the cases. These blends demonstrated better activity than the films prepared exclusively from the cationic copolymers (100 wt.\%). This could be explained by the fact the blends present high roughness, which increases the surface area and thus the surface contact with the microorganisms. In addition, the copolymers seem to migrate at the interface providing an enrichment of the copolymer at the surface, fact that also contributes to their enhanced antimicrobial activity. This is a simple method to prepare antimicrobial films by incorporating relatively low content of active copolymer into a low-cost matrix, and could be extended to other techniques such as spray coating or dip coating. This antimicrobial surface structure may provide new insights for the better designing of contact-active antimicrobial surfaces and could potentially be used as coating material in a wide range of biomedical or foodpackaging materials made of polystyrene. In addition,

\section{Acknowledgments}


This work was supported financially by the MINECO (Project MAT2016-78437-R). 


\section{References}

[1] A. S. Lynch, G. T. Robertson, Annual Review of Medicine 2008, 59, 415.

[2] S. L. Chua, L. D. Hultqvist, M. Yuan, M. Rybtke, T. E. Nielsen, M. Givskov, T. TolkerNielsen, L. Yang, Nature Protocols 2015, 10, 1165.

[3] R. Rajendran, L. Sherry, C. J. Nile, A. Sherriff, E. M. Johnson, M. F. Hanson, C. Williams, C. A. Munro, B. J. Jones, G. Ramage, Clinical Microbiology and Infection 2016, 22, 87.

[4] E. M. Hetrick, M. H. Schoenfisch, Chemical Society Reviews 2006, 35, 780.

[5] N. J. Hickok, I. M. Shapiro, Advanced Drug Delivery Reviews 2012, 64, 1165.

[6] L. E. Fisher, A. L. Hook, W. Ashraf, A. Yousef, D. A. Barrett, D. J. Scurr, X. Chen, E. F. Smith, M. Fay, C. D. J. Parmenter, R. Parkinson, R. Bayston, Journal of Controlled Release 2015, 202, 57.

[7] J. S. Lee, W. L. Murphy, Advanced Materials 2013, 25, 1173.

[8] D. Staneva, E. Vasileva-Tonkova, M. S. I. Makki, T. R. Sobahi, R. M. Abdel-Rahman, A. M. Asiri, I. Grabchev, Journal of Photochemistry and Photobiology B: Biology 2015, 143, 44.

[9] F. Costa, I. F. Carvalho, R. C. Montelaro, P. Gomes, M. C. L. Martins, Acta Biomaterialia 2011, 7, 1431.

[10] V. G. Correia, A. M. Ferraria, M. G. Pinho, A. Aguiar-Ricardo, Biomacromolecules 2015, $16,3904$.

[11] J. Gao, N. E. Huddleston, E. M. White, J. Pant, H. Handa, J. Locklin, ACS Biomaterials Science \& Engineering 2016, 2, 1169.

[12] A. J. Ryan, Nature Materials 2002, 1, 8.

[13] M. Álvarez-Paino, A. Muñoz-Bonilla, F. López-Fabal, J. L. Gómez-Garcés, J. P. A. Heuts, M. Fernández-García, Polym. Chem. 2015, 6, 6171.

[14] A. Muñoz-Bonilla, M. Fernández-García, Progress in Polymer Science 2012, 37, 281.

[15] A. Muñoz-Bonilla, M. Fernández-García, Eur. Polym. J. 2015, 65, 46.

[16] Y. Xue, H. Xiao, Y. Zhang, International journal of molecular sciences 2015, 16, 3626.

[17] Y. Jiao, L.-n. Niu, S. Ma, J. Li, F. R. Tay, J.-h. Chen, Prog. Polym. Sci. 2017, 71, 53.

[18] R. Tejero, D. López, F. López-Fabal, J. L. Gómez-Garcés, M. Fernández-García, Polym. Chem. 2015, 6, 3449.

[19] S. A. Rogers, E. A. Lindsey, D. C. Whitehead, T. Mullikin, C. Melander, Bioorganic \& Medicinal Chemistry Letters 2011, 21, 1257.

[20] A. Kamal, S. M. A. Hussaini, M. L. Sucharitha, Y. Poornachandra, F. Sultana, C. Ganesh Kumar, Org. Biomol. Chem. 2015, 13, 9388.

[21] R. Tejero, D. López, M. Fernández-García, European Polymer Journal 2015, 71, 401. 
[22] M. Alvarez-Paino, P. Bonilla, R. Cuervo-Rodríguez, F. López-Fabal, J. L. Gómez-Garcés, A. Muñoz-Bonilla, M. Fernández-García, European Polymer Journal 2017, 93, 53.

[23] M. Alvarez-Paino, R. Juan-Rodríguez, R. Cuervo-Rodríguez, R. Tejero, D. López, F. LópezFabal, J. L. Gómez-Garcés, A. Muñoz-Bonilla, M. Fernández-García, Colloids and Surfaces B: Biointerfaces 2016, 140, 94.

[24] ASTM E2149-01, Standard Test Method for Determining the Antimicrobial Activity of Immobilized Antimicrobial Agents Under Dynamic Contact Conditions (Withdrawn 2010), ASTM International, West Conshohocken, PA, 2001, www.astm.org.

[25] Q. L. Zhang, Hailong; Zhan, Xiaoli; Chen, Fengqiu; Yan, Jie; Tang, Hao, RSC Advances $2015,5,77508$.

[26] Z. L. Li, Daeyeon; Sheng, Xiaoxia; Cohen, Robert E.; Rubner, Michael F, Langmuir 2006, 22,9820 .

[27] L. Su, Y. Yu, Y. Zhao, F. Liang, X. Zhang, Scientific Reports 2016, 6, 24420

[28] R. B. Kugler, O.; Rondelez, F., Microbiology 2005, 151, 1341.

[29] F. Siedenbiedel, J. C. Tiller, Polymers 2012, 4, 46.

[30] M. S. Ganewatta, C. Tang, Polymer 2015, 63, A1.

[31] A. M. Bieser, J. C. Tiller, Macromolecular Bioscience 2011, 11, 526.

[32] K. Anselme, P. Davidson, A. M. Popa, M. Giazzon, M. Liley, L. Ploux, Acta Biomaterialia $2010,6,3824$.

[33] J. Mayr, J. Bachl, J. Schlossmann, D. Díaz, International Journal of Molecular Sciences $2017,18,303$.

\section{Table of Content}




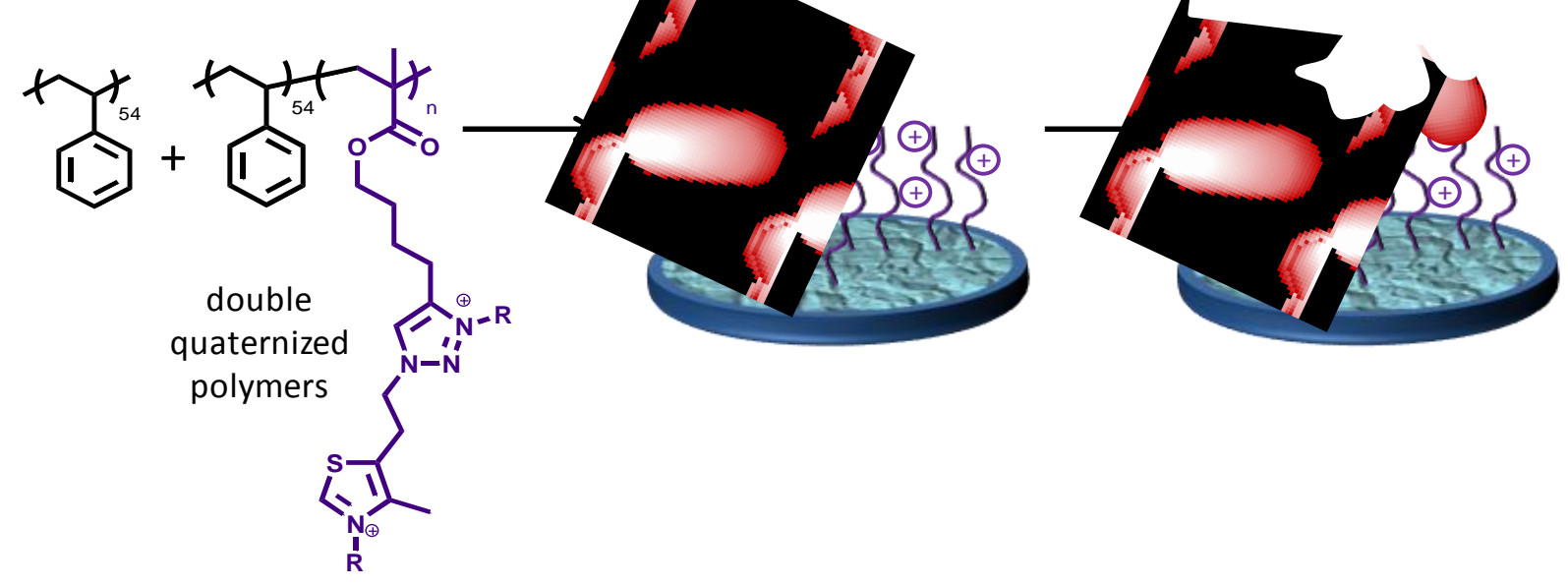

25 